\title{
EFFECTS OF OLEOTHERMAL TREATMENT AND POLYDIMETHYLSILOXANE (PDMS) COATING ON NATURAL WEATHERING OF BEECH AND FIR WOODS
}

\author{
Amir Mootab Saei ${ }^{1, \wedge}$, Behbood Mohebby ${ }^{2}$, Mohammad Reza Abdeh
}

\begin{abstract}
Effects of natural weathering on oleothermally treated wood and coated with an organic silicone compound were studied. Slats of beech and fir woods were cut in sizes of $20 \times 10 \times 1 \mathrm{~cm}$. The slats were treated by soybean oil at $230^{\circ} \mathrm{C}$ for $1 \mathrm{~h}$. Then, the half of the untreated and oleothermally treated slats were coated with polydimethylsiloxane (PDMS) and the rest of them were considered as control. All slats were hanged in $45^{\circ}$ angle at the southwest (SW) direction for 90 days. They were analyzed for color changes, roughness, and contact angle properties at 30-day intervals. Results showed that the oleothermal treatment of wood reduced discoloration of fir samples against natural weathering; however, the reducing effect was lower in the Beech samples. This treatment also reduced the surface roughness of the fir samples during weathering while it increased the surface roughness of beech. Wettability of the samples in both species, before and after weathering, was reduced by the oleothermal treatment. Results also revealed that coating of the wood surface with PDMS does not prevent the discoloration and surface roughness against weathering. Nevertheless, the coating could considerably decrease the hydrophilicity of the woods even after weathering.
\end{abstract}

Keywords: Contact angle, discoloration, natural weathering, oleothermal treatment, polydimethylsiloxane, roughness.

\section{INTRODUCTION}

In nature, wood is constantly exposed to biological and non-biological degradation agents. Weathering is a non-biological degradation which should not be confused with damage caused by biological agents. The main factors that led to the natural weathering of wood are including sunlight (especially ultraviolet light), humidity (rain, dew, and snow), temperature, atmospheric gases, such as oxygen and pollutant gases like sulfur dioxide and nitrogen dioxide. Photons in sunlight are the most important factor in weathering. Light absorption by the wood causes the formation of free radicals and the initiation of photochemical reactions at the surface. These reactions eventually cause discoloration, and subsequently roughness and cracking of the wood surface (Feist and Hon 1984, Feist 1990, Anderson et al. 1991, Williams et al. 2001, Williams 2005, Evans et al. 2005). Among wood's polymers, lignin is a UVabsorbent and the others (cellulose and hemicelluloses) have very little absorption (Norrstrom 1969, Williams 2010). Generally, light absorbing groups in lignin include phenolic hydroxyl, carbonyl and carboxyl groups. Aromatic and phenolic units, in the presence of light, act as sites for the initiation of radical chained reactions (Hon and Shiraishi 2001). In general, wood colour changes ( $\Delta \mathrm{E}^{*}$ values)

\footnotetext{
${ }^{1}$ Departament of Wood \& Paper Sciences, Faculty of Natural Resources, Tarbiat Modares University, Teherán, Irán.

2 Associate Professor. Dep. of Wood \& Paper Sciences, Faculty of Natural Resources, Tarbiat Modares University, Noor, Iran. Teherán, Irán. moebbyb@ modares.ac.ir

${ }^{3}$ Departament of Wood \& Paper Sciences, Faculty of Natural Resources, Tarbiat Modares University, Teherán, Irán. rezaabde@ gmail.com

^ Corresponding author: a.mootab.saei@gmail.com

Received: 11.12.2014 Accepted: 08.08.2015
} 
caused by weathering are directly correlated with lignin degradation rate and the formation of carbonyl groups (Pandey 2005b). On the other hand, light cannot penetrate the wood more than $200 \mu \mathrm{m}$. So, destructive reactions are limited to surface of the wood (Feist and Hon 1984, Hon and Shiraishi 2001), and wood can be protected by painting or coating with similar materials. Appearance of unprotected woods changes markedly in outdoor exposure within a few months. There are two basic methods to protect wood surfaces during outdoor weathering: (1) those that form a film, layer, or coating on the wood surface, and (2) those that penetrate the wood surface leaving no distinct layer or coating. Filmforming materials include paints of all description, varnishes, lacquers, and also overlays bonded to the wood surface. Penetrating finishes include preservatives, water repellents, pigmented semitransparent stains, and chemical treatments (Feist 1989).

In the most cases, wood properties are related to the chemistry of the cell wall and change by changing chemistry of cell wall polymers (Rowell 2007). Wood modification is a science that improves unpleasant properties of wood by changing its physical structure and chemical properties. Due to environmental concerns caused by some protective materials, wood modification has gained special attention these days. In general, the aims of wood modification are the reduction of moisture absorption, improving decay resistance, developing dimensional stability, increasing weathering resistance and etc (Hill 2006). Wood modification methods are including chemical, thermal, enzymatic and impregnation treatments. In the all treatments, the rate of water absorption is reduced by eliminating or limiting hydroxyl groups $(\mathrm{OH})$ and reduction of the hydrophilic parts in the polymers of cell wall's which consequently increase the biological durability and dimensional stability of the wood (Yan-Jun et al. 2002). In recent years, many studies have been done about the weathering resistance of woods modified by chemical and thermal methods. In the field of chemical modification, Rowell 2007 indicated that acetylation reduces wood weathering up to $50 \%$, because the acetylation protects wood against the weathering (Akhtari et al. 2007). Also, wood thermal modification in high temperatures greatly improves the durability of the wood against the weathering (Nuopponen et al. 2004, Ayadi et al. 2003). Thermal treatments affect the chemical structure of wood by heating in $160-260^{\circ} \mathrm{C}$ and change its physical and mechanical properties (Militz 2002).

Modifying the surface properties of wood using non-toxic and environmental friendly materials is another method that can be used to develop wood resistance against the natural weathering. Accordingly, various nonpolar agents, such as oils, waxes, silanes or silicones have been used to achieve water resistant surfaces (Ghosh et al. 2009b). In recent years, polydimethylsiloxane (PDMS) or silicones, as a hydrophobic agent, has gained special attention due to biocompatibility its optical and mechanical properties as well as its widespread industrial applications (Ghosh et al. 2009b). By analogy with ketones, the name "silicone" was given in 1901 by Kipping to describe new compounds of the formula $\mathrm{R}_{2} \mathrm{SiO}$ (Figure 1). These were rapidly identified as being polymeric and actually corresponding to polydialkylsiloxanes with the formulation:

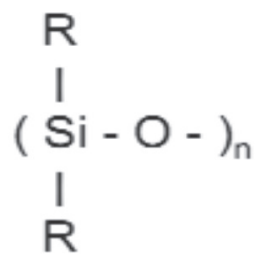

Figure 1. Polydialkylsiloxanes (Colas 2005). 
The name silicone was adopted by the industry and usually refers to linear polymers where $\mathrm{R}=\mathrm{Me}$ or polydimethylsiloxane (PDMS) (Figure 2):

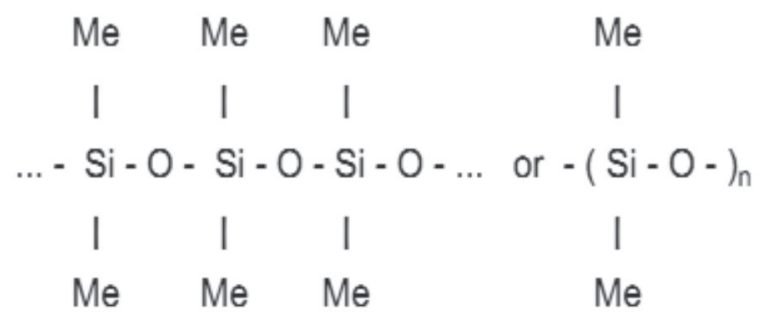

Figure 2. Polydimethylsiloxane (PDMS), (Colas 2005).

The methyl groups along the chain can be substituted by many other groups (e.g., phenyl, vinyl or trifluoropropyl). The simultaneous presence of "organic" groups attached to an "inorganic" backbone gives silicones a combination of unique properties and allows their application in many fields like aerospace (low and high temperature performance), electronics (electrical insulation), health care (excellent biocompatibility) or in the building industries (weathering resistance) (Colas 2005). Silicones or PDMS have been reported to improve hydrophobicity and dimensional stability of wood (Weigenand et al. 2007, Ghosh et al. 2009b). Studies have also shown that the functional groups of silicones can reduce the growth of blue stain fungi and moulds on wood surfaces (Ghosh et al. 2009a) and increase its resistance to fungal decay (Weigenand et al. 2008, Ghosh et al. 2009a).

The current study was aimed to evaluate the effect of oleothermal modification, as a treatment which changes the ability of PDMS coating, as a hydrophobic agent with high stability and industrial application, in protecting the surface of the oleothermally modified or unmodified woods was studied.

\section{MATERIALS AND METHODS}

\section{Samples preparation}

The slats of beech (Fagus orientalis) and fir (Abies sp.) wood species were cut into sizes of $20 \times 10 \times 1$ $\mathrm{cm}$ (20 samples for each species). The samples were divided into two groups; first group without treatment and second group were oleothermally treated by soybean oil at $230^{\circ} \mathrm{C}$ for $1 \mathrm{~h}$. The surfaces of the samples were sanded prior to coating. Afterwards, within each group, half of the slat samples (at least five specimens) were selected randomly and coated with PDMS (polydimethysiloxane, Merck, Germany) and the next half left uncoated. At least five slats were applied within the experiments for each sub-group.

\section{Natural weathering}

In order to study the effect of natural weathering (especially effect of sunlight), slats were exposed to the sunlight hanging on racks with a $45^{\circ}$ angle to the horizon at $\mathrm{SW}$ direction for 90 days (from midMarch until mid-June). In order to assess the effect of natural weathering on surface of the samples, colorimetric, roughness and contact angle properties were measured on the slats every 30 days intervals as explained below. 


\section{Colorimetric measurements}

Color changes of the samples were measured by a Sheen spectrophotometer equipped with a $\mathrm{D}_{65}$ light source and a standard detector $\left(10^{\circ}\right)$. The light wave length was in a visible range of $400-700 \mathrm{~nm}$. The data were collected based on ASTM 2244 in CIE L*a*b*. The CIE LAB provides a three-dimensional spectrum in which parameter $L^{*}$ indicates brightness in a range of $0-100$. A maximum brightness as 100 indicates whiteness and a minimum brightness as 0 indicates full darkness of the samples. Coordinates $\mathrm{a}^{*}$ and $\mathrm{b}^{*}$ are representing axes of $\mathrm{X}$ and $\mathrm{Y}$ respectively to indicate color change from red color $(+\mathrm{a})$ up to green color (-a) in axis $\mathrm{X}$ and from yellow color $(+\mathrm{b})$ to blue color $(-\mathrm{b})$ in axis $\mathrm{Y}$. The parameter $\Delta \mathrm{E}$ was also calculated to indicate any color changes during the weathering according to Equation 1 . In every measurement, 5 slats of each treatment were assayed with 4 recordings on each sample slats and results were reported as average.

$$
\begin{aligned}
& \Delta L^{*}=L_{2}{ }^{*}-L_{1}{ }^{*} \\
& \Delta a^{*}=a_{2}{ }^{*}-a_{1}{ }^{*} \\
& \Delta b^{*}=b_{2}{ }^{*}-b_{1}{ }^{*} \\
& \Delta E=\left(\Delta L^{* 2}+\Delta a^{* 2}+\Delta b^{* 2}\right)^{1 / 2}
\end{aligned}
$$

\section{Roughness analysis}

A HUATEC roughness meter SRT-6200 was applied to measure roughness of the slats during the exposure time. It measures $\mathrm{Ra}$ and $\mathrm{Rz}$ parameters in a cut off path line of $2,5 \mathrm{~mm}$. According to Figure 3 , Ra indicates average altitudes on the wood surface (Equation 2) and $\mathrm{Rz}$ indicates an average of 5 peaks and 5 valleys on the wood surface along the sensor path line (Equation 3). In the present research, Ra parameter was only used to measure the roughness of the samples. The roughness was assayed in 30-day interval with 9 recording on each slat (45 replicates for each treatment).

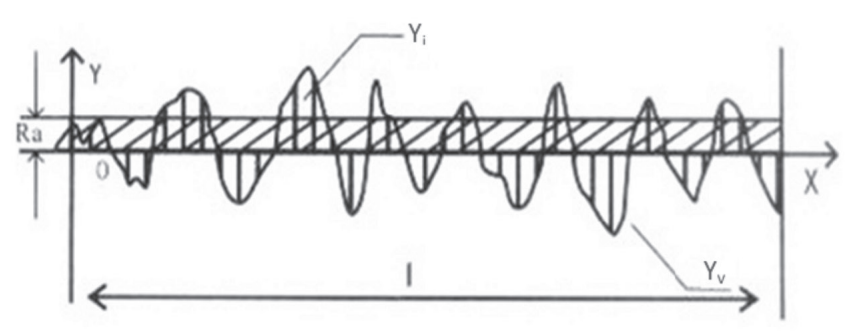

Figure 3. Diagram of surface roughness calculation.

$$
\begin{gathered}
R a=\frac{1}{n} \sum_{i=1}^{n}\left|Y_{i}\right| \quad(\text { Equation 2) } \\
R z=\frac{\sum_{i=1}^{5} Y_{i}+\sum_{i=1}^{5} Y_{v}}{5} \quad(\text { Equation 3) }
\end{gathered}
$$




\section{Contact angle evaluation}

The surface hydrophobicity of the slats was also determined with measuring water contact angle by a PG-X goniometer (Thwing Albert Instrument Co, USA) before and after the natural weathering. Dynamic contact angle was determined to measure wettability of the samples against the weathering. The volume of the water droplet was 3,5 $\mathrm{ml}$ and measurement time was $600 \mathrm{~s}$. The measurement was done 2 times on each slat surface and 10 times for each treatment.

\section{RESULTS AND DISCUSSION}

\section{Color changes}

Color parameters including $\mathrm{L}^{*}$ (brightness), $\mathrm{a}^{*}$ and $\mathrm{b}^{*}$ for beech and fir samples of different treatments before weathering (day 0 ) and during the weathering (days 30,60 and 90) are presented in tables 1 and 2 , respectively. Results showed that the beech samples $\left(L^{*}=56,8\right)$ were initially darker than fir woods $\left(L^{*}=81,5\right)$. Also, both oleothermal treatment and PDMS coating increased the color factors (especially the darkness) of the samples in both species. In general, the brightness $\left(\mathrm{L}^{*}\right)$ for all treatments was reduced by weathering during 90 days of natural weathering. Nevertheless, the brightness of the beech samples increased till day 30 and then decreased until the end of the study period. Primary color of wood samples (bright or dark) affects the intensity of their color changes caused by natural weathering (Feist 1992). At beginning of exposure to sunlight, dark woods get brighter by natural weathering and bright woods get darker. However, the color of both dark and bright woods goes toward dark gray after several months (Feist 1992). Treatments used to protect wood surface against weathering can also affect wood color and make it darker (Tables $1 \& 2$ ). Other studies have also showed that thermal modification of wood can make it darker (Dubey et al. 2011, Xian-Jun et al. 2011). Any color change due to heat treatments depends on the intensity of the treatment and wood species (Yixing et al. 1994) and reflects chemical changes in the wood (Todorovic et al. 2012). Some compounds produced with thermal degradation of lignin and hemicellulose causes the color change in wood (Gonzalez-Pena and Hale 2009). Moreover, elimination or the movement of low molecular weight substances from the inside to the wood surface will change the wood color during oleothermal treatment. Ghosh et al. 2009a, also showed that different silicon solutions including PDMS caused the reduction of $\mathrm{L}^{*}$ and finally the darkness of the samples. 
Table 1. Changes in color parameters $(\mathrm{L} * \mathrm{a} * \mathrm{~b} *)$ in treatments and during natural weathering in Beech.

\begin{tabular}{|c|c|c|c|c|c|}
\hline \multirow{2}{*}{ Treatments } & \multirow{2}{*}{$\begin{array}{c}\text { Color } \\
\text { coordinates }\end{array}$} & \multicolumn{4}{|c|}{ Days } \\
\hline & & 0 & 30 & 60 & 90 \\
\hline \multirow{6}{*}{ UN } & $\mathrm{L}^{*}$ & 56,8 & 57,2 & 46,4 & 43,0 \\
\hline & STDV & $\pm 1,6$ & $\pm 2,1$ & $\pm 4,3$ & \pm 4 \\
\hline & $a^{*}$ & 12,8 & 7,6 & 4,7 & 3,8 \\
\hline & STDV & $\pm 1,2$ & $\pm 1,5$ & $\pm 0,9$ & \pm 1 \\
\hline & $b^{*}$ & 21,16 & 23 & 16,8 & 11,4 \\
\hline & STDV & $\pm 1,6$ & $\pm 1,7$ & $\pm 1,6$ & $\pm 1,2$ \\
\hline \multirow{6}{*}{ UN+PDMS } & $\mathrm{L}^{*}$ & 43 & 48,5 & 40,6 & 37,2 \\
\hline & STDV & $\pm 2,7$ & $\pm 3,3$ & $\pm 4,1$ & $\pm 3,8$ \\
\hline & $a^{*}$ & 17,6 & 11,9 & 7,5 & 5,2 \\
\hline & STDV & $\pm 1,5$ & $\pm 1,2$ & $\pm 0,8$ & $\pm 0,8$ \\
\hline & $b^{*}$ & 25,6 & 26,4 & 19,3 & 13,5 \\
\hline & STDV & $\pm 2,5$ & $\pm 1,7$ & $\pm 1,8$ & $\pm 0,8$ \\
\hline \multirow{6}{*}{ ОНТ } & $L^{*}$ & 43,1 & 51,7 & 46,9 & 39,8 \\
\hline & STDV & $\pm 6,2$ & \pm 5 & $\pm 3,9$ & $\pm 4,4$ \\
\hline & $a^{*}$ & 14 & 10 & 6,2 & 3,8 \\
\hline & STDV & $\pm 1,3$ & $\pm 1,4$ & $\pm 1,2$ & $\pm 0,8$ \\
\hline & $b^{*}$ & 22,6 & 26,0 & 20,2 & 12,6 \\
\hline & STDV & \pm 3 & $\pm 1,4$ & $\pm 1,5$ & $\pm 0,7$ \\
\hline \multirow{6}{*}{ OHT+PDMS } & $\mathrm{L}^{*}$ & 36,8 & 51,4 & 43,4 & 36,8 \\
\hline & STDV & $\pm 4,4$ & \pm 2 & $\pm 2,6$ & $\pm 2,9$ \\
\hline & $a^{*}$ & 15,8 & 11,1 & 6,3 & 4,2 \\
\hline & STDV & \pm 2 & $\pm 0,9$ & $\pm 0,7$ & $\pm 0,5$ \\
\hline & $\mathrm{b}^{*}$ & 22,7 & 27,8 & 20,1 & 13,4 \\
\hline & STDV & $\pm 1,7$ & $\pm 2,1$ & $\pm 1,8$ & $\pm 1,1$ \\
\hline
\end{tabular}

Table 2, Changes in color parameters $(\mathrm{L} * \mathrm{a} * \mathrm{~b} *)$ in treatments and during natural weathering in Fir.

\begin{tabular}{|c|c|c|c|c|c|}
\hline \multirow{2}{*}{ Treatments } & \multirow{2}{*}{$\begin{array}{c}\text { Color } \\
\text { coordinates }\end{array}$} & \multicolumn{4}{|c|}{ Days } \\
\hline & & 0 & 30 & 60 & 90 \\
\hline \multirow{6}{*}{ UN } & $\mathrm{L}^{*}$ & 81,5 & 65,3 & 56,7 & 51,4 \\
\hline & STDV & $\pm 1,2$ & $\pm 2,4$ & $\pm 1,8$ & $\pm 2,9$ \\
\hline & $a^{*}$ & 1,6 & 6,5 & 4,5 & 3,6 \\
\hline & STDV & $\pm 0,9$ & $\pm 1,7$ & $\pm 1,1$ & $\pm 1,4$ \\
\hline & $\mathbf{b}^{*}$ & 17,4 & 28,2 & 18,6 & 13,1 \\
\hline & STDV & $\pm 1,5$ & $\pm 1,6$ & \pm 2 & $\pm 1,2$ \\
\hline \multirow{6}{*}{ UN+PDMS } & $\mathbf{L}^{*}$ & 75,3 & 61,8 & 51,2 & 43,7 \\
\hline & STDV & $\pm 1,7$ & $\pm 1,4$ & $\pm 1,7$ & $\pm 1,6$ \\
\hline & $a^{*}$ & 3,3 & 8,6 & 7,3 & 6,3 \\
\hline & STDV & $\pm 1,5$ & $\pm 1,9$ & $\pm 0,9$ & \pm 1 \\
\hline & $\mathbf{b}^{*}$ & 24 & 33,6 & 26 & 17,9 \\
\hline & STDV & $\pm 2,6$ & $\pm 1,9$ & $\pm 2,1$ & $\pm 1,6$ \\
\hline \multirow{6}{*}{ ОНТ } & $\mathbf{L}^{*}$ & 71,4 & 65,3 & 57,2 & 52,1 \\
\hline & STDV & $\pm 2,8$ & $\pm 2,1$ & $\pm 2,3$ & $\pm 2,4$ \\
\hline & $a^{*}$ & 7,9 & 7,8 & 4,8 & 3 \\
\hline & STDV & $\pm 1,9$ & $\pm 1,3$ & \pm 1 & \pm 1 \\
\hline & $\mathbf{b}^{*}$ & 25,7 & 29,4 & 19,4 & 13 \\
\hline & STDV & $\pm 2,3$ & $\pm 2,7$ & $\pm 2,9$ & $\pm 1,4$ \\
\hline \multirow{6}{*}{ OHT+PDMS } & $\mathbf{L}^{*}$ & 69,1 & 63,3 & 52 & 44,9 \\
\hline & STDV & $\pm 5,2$ & $\pm 2,3$ & $\pm 3,1$ & $\pm 3,1$ \\
\hline & $a^{*}$ & 8,7 & 8 & 6 & 4,4 \\
\hline & STDV & $\pm 2,9$ & \pm 1 & \pm 1 & $\pm 0,9$ \\
\hline & $\mathbf{b}^{*}$ & 28,9 & 32,6 & 21,2 & 14,7 \\
\hline & STDV & $\pm 2,1$ & $\pm 2,6$ & \pm 2 & $\pm 1,3$ \\
\hline
\end{tabular}

Figures 4 and 5 show total color change $(\Delta \mathrm{E})$ of fir and beech woods due to the natural weathering during the study period. According to the results, the gradient of changes in $\Delta \mathrm{E}$ value in fir samples was more than beech ones (except oleothermally treated beech wood coated with PDMS which had a relatively large color change in the first 30 days that is related to the changes observed for coordinate $\mathrm{L}^{*}$ in the samples (Table 1). In general, the type of wood species (hardwood or softwood) as well as the amount of extractives migrated from innermost of the wood, affect the rate of photochemical reactions and the intensity of color change (Pandey 2005a). As Pandey 2005b, explained because of differences in the structural units of softwood and hardwood especially in lignin and hemicelluloses, the color changes due to the weathering are not the same. In general, hardwood lignin termed as guaiacyl-syringyl lignin consists of coniferyl alcohol and sinapyl alcohol derived units in varying ratios; whereas in softwood lignin which is usually referred to as guaiacyl lignin, the structural elements are derived principally from coniferyl alcohol. In this research, it might also be expected that the formation of carbonyl groups during softwood lignin degradation, should be more than the hardwood lignin. 


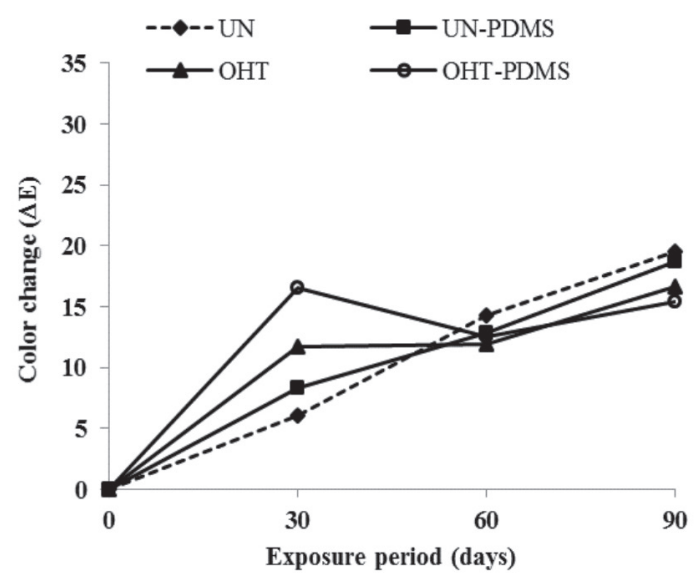

Figure 4. Color change in beech samples due to natural weathering.

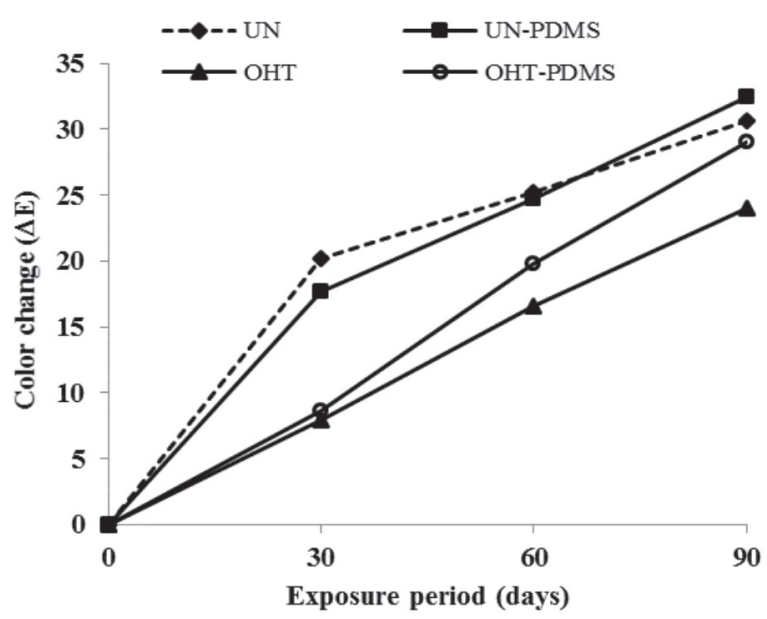

Figure 5. Color change in fir samples due to natural weathering.

According to the results shown in figures 4 and 5, it seems that oleothermal treatment of wood could more effectively improve its resistance to the color change caused by weathering in fir samples. According to the same reports, lignin is altered chemically during the thermal modification through condensation and cross-linking reactions limiting free radical formation during weathering and related reactions on wood surface. On the other hand, such structure in lignin prevents leaching and ease removal of the products caused by photochemical degradation of wood surface (Nuopponen et al. 2004, Ayadi et al. 2003). Moreover, degradation of lignin molecules due to the heat treatments causes to increase phenolic monomers preventing less free radical formation during weathering. Because, this phenomenon limits the reaction of oxygen and radicals (Ayadi et al. 2003). Also, oil uptake by wood during the treatment and the formation of oil layer on the wood surface, cause to reduce intensity of color change (Dubey et al. 2010). 
As can be seen in all treatments, beech samples have also experienced a quite different color changes compared with the fir samples. According to table 1 , coordinate $L^{*}$ has increased within the first 30 days for all treatments and color change has subsequently increased in the samples (Figure 4). It should also be taken into account that darker samples (with less amounts of $\mathrm{L}^{*}$ ) became lighter (higher $\mathrm{L}^{*}$ ) after 30 days of expoure. The same results were also observed for PDMS coated samples. The oleothermal treated samples and coated with PDMS at 1st day had less $\mathrm{L}^{*}$ and after 30 days showed the most color change.

Unlike the beech samples for the fir samples, coating the wood with PDMS had no significant effect in protecting wood surface against the UV light and resistance against the color change caused by the natural weathering in the oleothermally treated samples. The same results were also reported by Ghosh et al. 2009a, who has expressed that silicone emulsions did not improve the color stability.

\section{Roughness (Ra)}

The results of the surface roughness based on Ra factor within 90 days of the natural weathering for two species of beech and fir woods are shown in figures 6 and 7, respectively. Surface roughness of beech samples (in all treatments) prior to natural weathering (day zero) was more than fir samples due to its coarse texture. In general, the surface roughness of the samples before the weathering is related to their anatomy and how they are prepared (Thoma et al. 2015). In this experiment, machining and preparation of all samples were similar. Hence, the observed differences in surface roughness at the first day, is related to the structural differences between both species, because beech has the great vessels and fir has tracheid.

This is accepted that wood surfaces due to weathering in short time period (a few months) are afoul roughness. This is important because surface roughness can influence the final coating performance of samples (Williams and Feist 1994). Results showed that the roughness of untreated beech and fir samples increased after the first exposure time (30 days). However, after this period the observed trend changed and the roughness of fir samples slightly reduced while the surface roughness of beech wood did not change until the end of the exposure time. The main reasons for wood surface roughness are degradation of wood polymers caused by photochemical reactions and/or exit of material from wood as a result of compound leaching caused by light damage during natural weathering reactions (Feist 1982). Absorption and desorption of moisture and change in wood dimension due to fluctuations in relative humidity of environment also cause small cracks and even gaps in the wood surface which in turn increase surface roughness (Chang et al. 1982). As mentioned, according to the difference between structural units of hardwoods and softwoods especially lignin, it seems that the leaching of compounds caused by photochemical degradation of surface of fir samples and exposure of their internal layers against the weathering may explain their softening. As fir samples have thinner walled cells and lower density than beech samples; they might be subjected to leaching faster than the beech. Regarding the effective factors on the surface roughness of wood that appear during the photochemical reactions and dimensional changes due to the humidity, it is expected that the surface roughness of wood can be reduced by controlling photochemical reactions and creating dimensional stability. Thermal treatments (Ayadi et al. 2003, Boonstra and Tjeerdsma 2006) and the use of silicon compounds (Mai and Militz 2004) are methods that cause dimensional stability of wood. In other hand, findings of other researchers determined that wood treatment by heat can reduce photochemical reactions, degradation of wood organic polymer caused by the weathering and the exit of material from wood surface (Nuopponen et al. 2004). Our results showed that the surface roughness of the oleothermally treated beech samples during the natural weathering (30 days period) were relatively more than the fir samples. During the next second 30 days, both species had a relatively stable trend, but at the last period surface roughness was reduced, especially in beech samples. Little information about the surface roughness of modified woods by heat against the weathering is available. Nevertheless, the observed reduction in the surface roughness of oleothermally treated woods may be related to the reduction of exit materials from wood surface due to the reduction of the rate of photochemical reactions and achieving higher dimensional stability. Also, the observed difference in the surface roughness of oleothermally treated beech and fir samples can be 
related to their new structure after the oleothermal treatment. Other studies also determined that weight loss due to thermal treatments in softwood samples is more than hardwood samples and this difference is related to the type and amount of their hemicelluloses. Pentosans (are found in hardwoods in a high proportion) are more sensitive to thermal treatments compared to hexosans (are found in softwoods) (Hill 2006, Kol and Sefil 2011). More degradation of wood polymers due to thermal treatments increases the probability of the exit of their compounds against surface leaching during the natural weathering.

As shown in figures 6 and 7, the use of PDMS could not prevent increasing the surface roughness of the samples. Only oleothermally treated fir samples had good resistance against the weathering. In a similar study, Ghosh et al. 2009a evaluated the surface roughness of samples treated with different emulsions. Finally, they concluded that low concentration of emulsions could not affect the surface roughness of the woods while their high concentration could prevent from surface roughness and cracks in the surface of the samples.

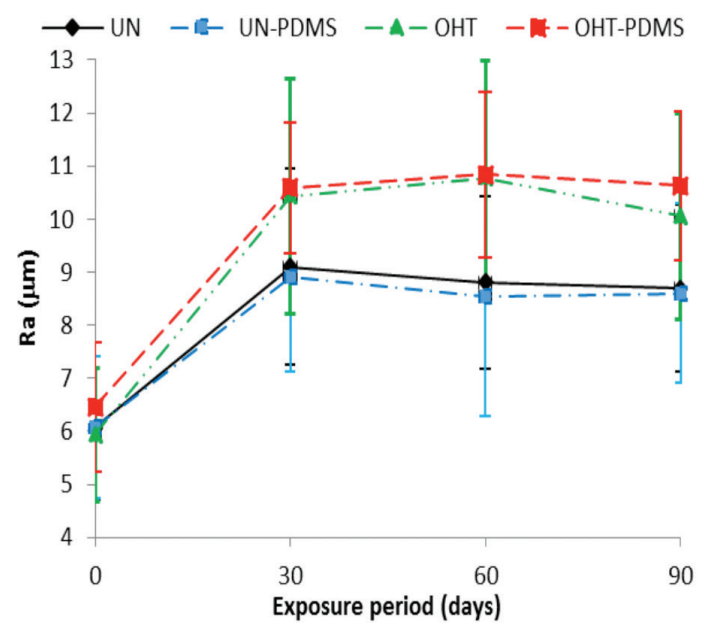

Figure 6. Surface roughness in beech samples due to natural weathering.

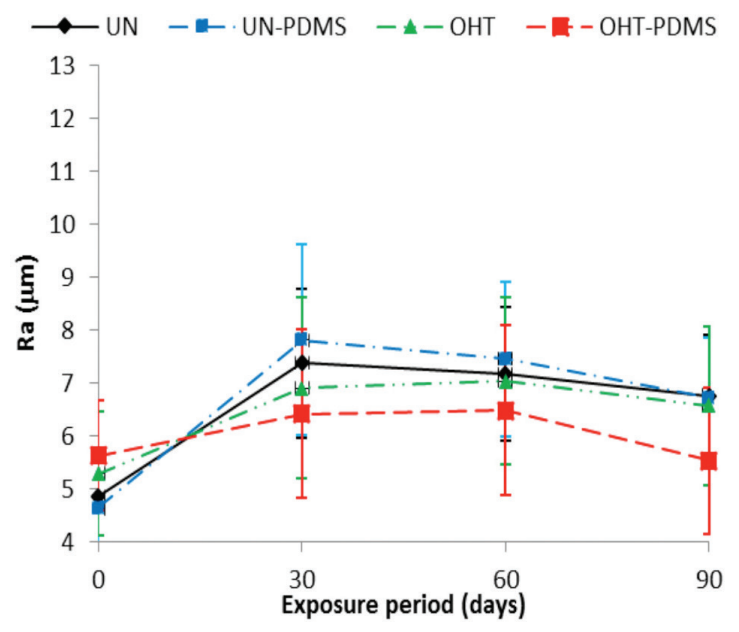

Figure 7. Surface roughness in fir samples due to natural weathering. 


\section{Dynamic contact angle}

Contact angle of water droplets with a solid surface usually are named wettability and small contact angle will show more wettability which an indicating more surface tensions. Dynamic contact angle of water droplets with the sample surfaces, before and after the weathering, are shown in Figure 8. The results showed that the dynamic contact angle in the surface of untreated samples of beech and fir wood decreased considerably after the weathering and reached to $0^{\circ}$ after a short time (Figure $8 \mathrm{~A}$ and $\mathrm{B}$ ). In other words, it can be conclude that the wettability of the untreated sample of beech and fir strongly increased against the weathering. Different structural and chemical changes that occur in wood surface in the effect of photochemical reactions during the weathering cause the reduction of contact angle and increasing the wettability of wood surface. Increased cellulose and hydroxyl groups in the effect of lignin degradation and its exit from wood surface are among the most important reasons (Kalinins and Feist 1993, Kishino and Nakano 2004). Figure 8C and D show the wettability of oleothermally treated wood samples before and after the weathering for both beech and fir species. Comparing to the untreated samples, dynamic contact angle of oleothermally treated samples before the weathering was higher that coincides with others' results (Esteves and Pereira 2009). Petrissans et al. 2003, explained that probably increase the crystallinity of cellulose during the thermal treatments cause increase the contact angle and the reduction of wood wettability. Hakkou et al. 2005, also reported that natural reactions and increasing the amount of extractive materials cannot cause increasing the surface hydrophilicity. By studying CPMAS NMR and FTIR, they suggested that the increased wettability can be related to the formation of wood biopolymers due to the reduction of residual water and likely the plasticization of lignin. Hill 2006, also believed that the reduction of wettability in the low temperatures is due to the moving lipophilic extractive materials to the surface and in the high temperatures is due to the reduction of hydroxyl groups. It can be concluded that increased percentage of lignin in the surface, the degradation of hygroscopic ingredients (hemicelluloses and amorphous cellulose), and the dehydrogenation reactions occurring during the thermal wood treatments can cause to reduction of hydrophilicity and surface wettability. Change in the amount of extractive materials can be also important.

Also results presented in figure $8 \mathrm{C}$ and $\mathrm{D}$ showed that oleothermal treatment of wood at $230^{\circ} \mathrm{C}$ with 1 $\mathrm{h}$ treatment time reduced the wettability caused by the weathering in the samples. As noted, degradation of lignin due to the photochemical reactions and followed by surface leaching in the effect of rainwater, dew and fog cause the exit of compounds created by lignin degradation from surface which increase the amount of surface cellulose (Evans et al. 2005). Cellulose increase wood surface hydrophilicity. It seems that oleothermal treatment of wood (especially in beech samples) could prevent leaching and exit of the compounds from wood surface (Nuopponen et al. 2004).

As mentioned in the introduction, wood treatment with silicon compounds can cause hydrophobic surface and improve the wetting properties of wood (Weigenand et al. 2007, Ghosh et al. 2009b). Figure $8 \mathrm{E}$ and $\mathrm{F}$ for untreated samples and coated with PDMS as wellas Figure $8 \mathrm{G}$ and $\mathrm{H}$ for oleothermally treated samples and coated with PDMS show that unlike the colorimetric test and surface roughness, PDMS could significantly reduce the hydrophilicity of wood surface. Moreover, PDMS could show good resistance against the natural weathering and treated samples with PDMS had high performance after the exposure time (90 days). 


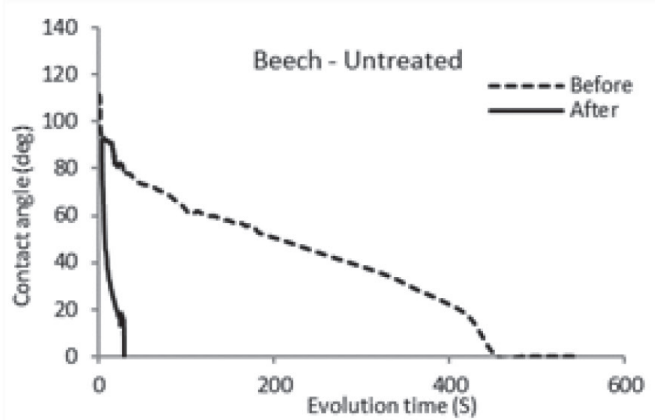

(A)

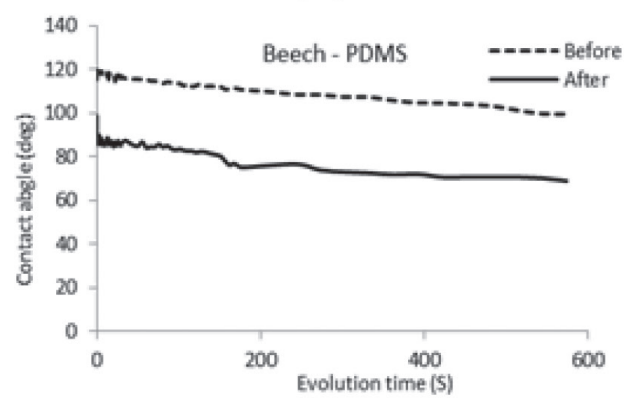

(C)

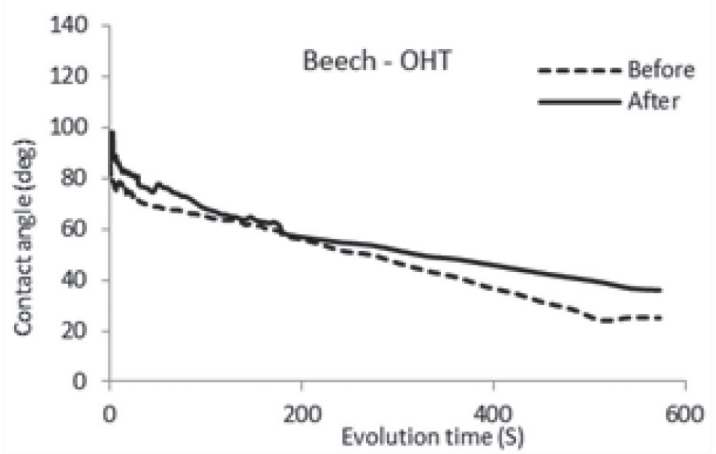

(E)

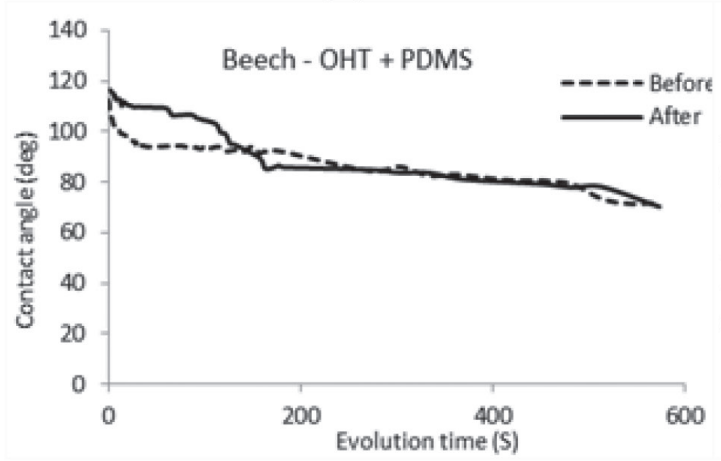

(G)

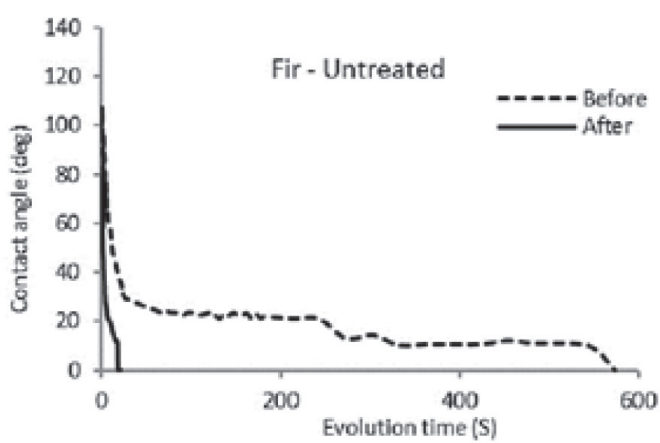

(B)

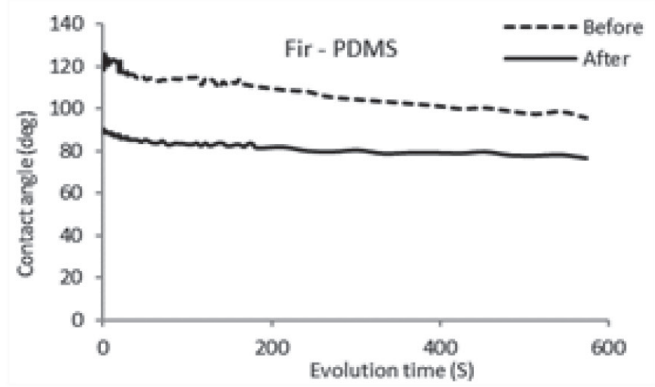

(D)

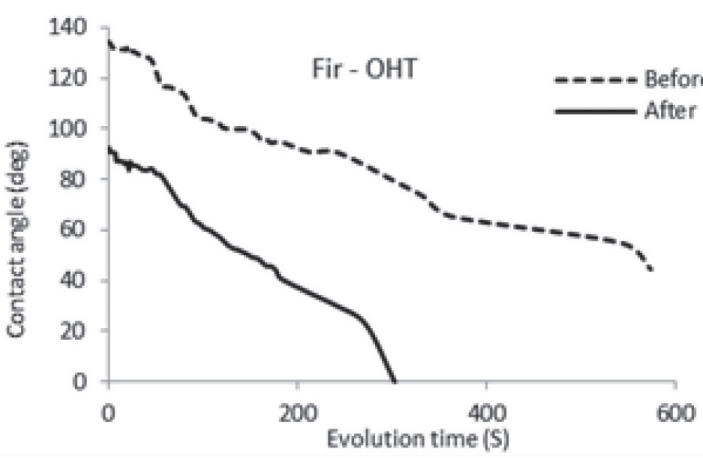

(F)

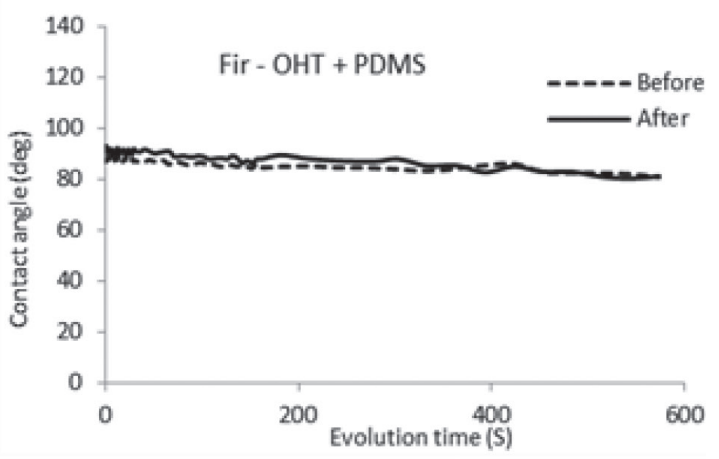

(H)

Figure 8. Dynamic contact angle of beech and fir samples before and after weathering; A, B: Untreated samples; C, D: coated with PDMS; E, F: Oil Heat treated samples; G, H: Oil 


\section{CONCLUSIONS}

Exposing wood to natural weathering causes discoloration and increases its roughness and surface wettability after a short period. In this study, oleothermal treatment of wood showed that the degradation intensity of the treated woods against the natural weathering would be species dependent. After the 90 days of exposure to the natural weathering, oleothermally treated samples showed less color change than untreated samples and also the treatment of wood caused increase of the surface roughness in the beech samples and reduction in the fir samples. Moreover, the hydrophilicity and wettability of the oleothermally treated surface, before and after the weathering in both species were reduced. Coating the surface of the samples by PDMS could not affect their resistance against the color change and surface roughness due to the natural weathering while their surface wettability was considerably reduced.

\section{REFERENCES}

Akhtari, M.; Hemmasi, A.H.; Mirshokraie, S.A.; Arefkhani, M. 2007. Infrared Studies of Weathering in Acetylated Beech Wood, European Conference on Wood Modification, 217-220.

Anderson, E.L.; Pawlak, Z.; Owen, N.L.; Feist, W.C. 1991. Infrared Studies of Wood Weathering. Part I: Softwoods. Applied Spectroscopy 45(1):641-647.

Ayadi, N.; Lejeune, F.; Charrier, F.; Charrier, B.; Merlin, A. 2003. Color Stability of Heat-treated Wood during Artificial Weathering. Holz als Roh- und Werkstoff 61:221-226.

Boonstra, M.J.; Tjeerdsma, B. 2006. Chemical Analysis of Heat Treated Softwoods. Holz als Roh-und Werkstoff 64:204-211.

Chang, S.T.; Hon, D.N.S.; Feist, W.C. 1982. Photodegradation and Photoprotection of Wood Surfaces. Wood and Fiber Science 14(2):104-117.

Colas, A. 2005. Silicones: Preparation, Properties and Performance.

Dubey, M.K.; Pang, S.; Walker, J. 2010. Color and Dimensional Stability of Oil Heat-Treated Radiata Pinewood after Accelerated UV Weathering. Forest Prod J 60:453-459.

Dubey, M.K.; Pang, S.; Walker, J. 2011 Effect of oil heating age on colour and dimensional stability of heat treated Pinus radiata. Eur J Wood Prod 69:255-262.

Esteves, B.M.; Pereira, H.M. 2009. Wood Modification by Heat Treatment: A Review. BioResources 4:370-404.

Evans, P.; Chowdhury, M.J.; Mathews, B.; Schmalzl, K.; Ayer, S.; Kiguchi, M.; Kataoka, Y. 2005. Weathering and Surface Protection of Wood. In: Kutz M., ed. Handbook of Environmental Degradation of Materials. William Andrew Publishing, Norwich, 277-297.

Feist, W.C. 1982. Weathering of Wood in Structural Uses. In: Structural Use of Wood in Adverse Environments. Meyer,R.W. and Kellogg, R.M. (Ed.). Society of Wood Science and Technology. Van Nostrand Reinhold Co., New York, NY. pp. 156-178.

Feist, W.C. 1989. Painting and Finishing Wood for use Outdoors, Proceedings of Seventh Annual Educational Conference, p. A1-A27. 
Feist, W.C. 1990. Archaeological Wood: Properties, Chemistry, and Preservation. Proceedings of 196th meeting of the American Chemical Society, Los Angeles. Washington: p. 263-298.

Feist, W.C. 1992. Natural Weathering of Wood and its Control by Water-Repellent Preservatives. American Painting Contractor 69:18-25.

Feist, W.C.; Hon, D.N.S. 1984. Chemistry of Weathering and Protection, In: Rowell R.M.: The Chemistry of Solid Wood, Advances in Chemistry. Series 207, American Chemical Society, Washington D.C.: pp. 401-454.

Ferist, S.C.; Militz, H.; Mai C. 2009a. Natural Weathering of Scots Pine (Pinus sylvestris L.) Wood Modified by Functionalized Commercial Silicone Emulsions. European Conference on Wood Modification, Stockholm, Sweden, on 27-29 ${ }^{\text {th }}$ April, 253-260.

Ghosh, S.C.; Militz, H.; Mai, C. 2009b. The efficacy of commercial silicones against blue stain and mould fungi in wood. Eur J Wood Prod 67:159-167.

Gonzalez-Pena, M.M.; Hale, M.D.C. 2009. Colour in thermally modified wood of beech, Norway spruce and Scots pine. Part 1: Colour evolution and colour changes. Holzforschung 63:385-393.

Hakkou, M.; Petrissans, M.; Zoulalian, A.; Gerardin, P. 2005. Investigation of Wood Wettability Changes during Heat Treatment on The Basis of Chemical Analysis. Polymer Degradation and Stability $89: 1-5$.

Hill, C.A.S. 2006. Wood Modification, Chemical, Thermal and Other Processes. John Wiley \& Sons Ltd, England: p. 239.

Hon, D.N.S.; Shiraishi, N. 2001. Wood and Cellulosic Chemistry. Second edition; Marcel Dekker, Inc.: NewYork.

Kalnins, M.A.; Feist, W.C. 1993. Increase in Wettability of Wood with Weathering. Forest Prod J 43:55-57.

Kishino, M.; Nakano, T. 2004. Artificial Weathering of Tropical Woods. Part 1: Changes in Wettability. Holzforschung 58:552-557.

Kol, H.S.; Sefil, Y. 2011. The Thermal Conductivity of Fir and Beech Wood Heat Treated at 170, 180, 190, 200, and $212^{\circ}$ C. Journal of Applied Polymer Science 121:2473-2480.

Mai, C.; Militz, H. 2004. Modification of Wood with Silicon Compounds. Inorganic Silicon Compounds and Sol-Gel Systems: a review. Wood Sci Technol 37:339-348.

Militz, H. 2002. Thermal treatment of wood: European Processes and their Background. The International Research Group on Wood Preservation; IRG Document No. IRG/WP 02-40241.

Norrstrom, H. 1969. Light Absorbing Properties of Pulp and Paper Components. Svensk Paperstidn 72: $25-3$.

Nuopponen, M.; Wikberg, H.; Vuorinen, T.; Maunu, S.L.; Jamsa, S.; Viitaniem, P. 2004. HeatTreated Softwood Exposed to Weathering. Journal of Applied Polymer Science 91:2128-2134. 
Pandey, K.K. 2005a. A Note on the Influence of Extractives on the Photo-Discoloration and PhotoDegradation of Wood. Polymer Degradation and Stability 87:375-379.

Pandey, K.K. 2005b. Study of the Effect of Photo-Irradiation on the Surface Chemistry of Wood. Polymer Degradation and Stability 90:9-20.

Petrissans, M.; Gerardin, P.; El Bakali, I.; Serraj, M. 2003. Wettability of Heat-Treated Wood. Holzforschung 57:301-307.

Rowell, R.M. 2007. Chemical Modification of Wood, In: Fakirov S., Bhattacharyya D. (Eds.): Handbook of Engineering Biopolymers: Homopolymers, Blends and Composites. Hanser Gardner Publications, Cincinnati: pp. 673-691.

Thoma, H.; Peri, L.; Lato, E. 2015. Evaluation of wood surface roughness depending on species characteristics. Maderas. Ciencia y Tecnología 17(2):285-292.

Todorovic, N.; Popovic, Z.; Milic, G.; Popadic, R. 2012. Estimation of Heat-Treated Beechwood Properties by Color Change. BioResources 7(1):799-815.

Weigenand, O.; Humar, M.; Daniel, G.; Militz, H.; Mai, C. 2008. Decay resistance of wood treated with amino-silicone compounds. Holzforschung 62(1):112-118.

Weigenand, O.; Militz, H.; Tingaut, P.; Sèbe, G.; De Jeso, B.; Mai, C. 2007. Penetration of amino-silicone micro- and macro-emulsions into Scots pine sapwood and the effect on water related properties. Holzforschung 61(1):51-59.

Williams, R.S. 2005. Weathering of wood. In: Rowell, R.M., ed. Handbook of Wood Chemistry and Wood Composites. Boca Raton: CRC Press. Chapter 7.

Williams, R.S. 2010. Finishing of wood. In: Wood Handbook. General Technical Report FPLGTR-190. Madison, WI: U.S. Department of Agriculture, Forest Service, Forest Products Laboratory, Chapter 16:1-39.

Williams, R.S.; Feist, W.C. 1994. Effect of Preweathering, Surface Roughness, and Wood Species on the Performance of Paint and Stains. Journal of Coatings Technology 66(828):109-121.

Williams, R.S.; Knaebe, M.T.; Feist, W.C. 2001. Erosion Rates of Wood during Natural Weathering. Part II. Earlywood and Latewood Erosion Rates. Wood and Fiber Science 33:43-49.

Xian-Jun, L.; Zhiyong, C.; Qunying, M.; Yiqiang, W.; Yuan, L. 2011. Effects of Heat Treatment on Some Physical Properties of Douglas Fir (Pseudotsuga menziesii) Wood Advanced Materials Research 197-198:90-95.

Yan-Jun, X.; Yi-Xing, L.; Yao-Xing, S. 2002. Heat-Treated Wood and its Development in Europe. Journal of Forestry Research 13:224-230.

Yixing, L.; Jian, L.; Jinman, W.; Jinsong, Y.; Yanhua, M. 1994. The effect of heat treatment on different species wood colour. $J$ Forest Res 5(4):73-78. 